\title{
LA CONSTRUCCIÓN SOCIAL DEL PERSONAJE EN LA VIDA COTIDIANA: UN ESTUDIO POLIÉDRICO SOBRE LETIZIA ORTIZ. O LA REINA DEL PUEBLO
}

\author{
Borja Oliva Mederos \\ Universidad de La Laguna
}

http://dx.doi.org/10.5209/NOMA.53296

\begin{abstract}
Resumen.- Este novedoso y original trabajo de investigación pretende asentar una primera base que permita el examen riguroso de la construcción de un personaje en concreto. Este estudio aborda la presentación sobre la actual Reina de España, Letizia Ortiz, a partir de la producción de noticias por parte de los periodistas y de los medios de comunicación, que realizan los periódicos $A B C$ y El País, además de la revista semanal Hola, en un determinado periodo, que abarca desde septiembre a diciembre del 2014. Todo ello, elaborando un modelo que debiera combinar los enfoques de la economía política, desde la visión estructural, y de los estudios culturales, en un marco analítico textual. El objetivo es desentrañar el esquema de un poliedro, teniendo en cuenta en el proceso, tanto la producción como la importancia del "canal", es decir, del mensaje y su soporte.
\end{abstract}

Palabras clave: Economía política, estudios culturales, Letizia Ortiz, medios de comunicación, personaje, poliedro.

Abstract.- This innovative and original research seeks to establish a first basis for the scrutiny of the construction of a particular character. This study addresses the presentation on the current Queen of Spain, Letizia Ortiz, from the production of news by journalists and the media, which made the newspapers $A B C$ and El Pais, in addition to the weekly magazine Hello, in a given period, which runs from September to December 2014. all this, developing a model which combines the approaches of political economy, from the structural view, and cultural studies, textual analytical framework. The goal is to unravel the scheme of a polyhedron, taking into account in the process, both the production and the importance of the "channel", so, the message and its support.

Keywords: Character, cultural studies, Letizia Ortiz, media, political economy, polyhedron.

Índice

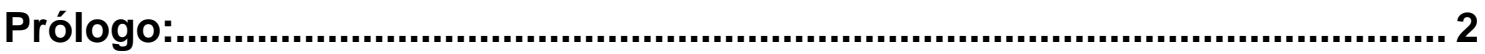

Modelo poliédrico: ...................................................................................... 4

Productores y periodistas: ......................................................................... 9

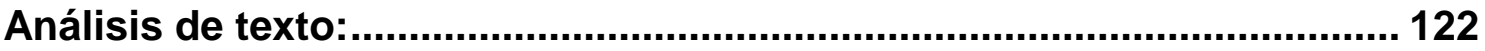

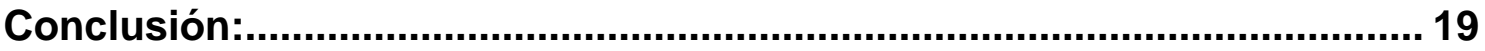

Referencias bibliográficas:..................................................................... 19 


\section{Prólogo:}

Detrás de este "proyecto" de investigación hay un largo ensamblaje de intencionalidad académica para demostrar las habilidades y capacidades adoptadas por el alumnado durante los cuatro años cursados en un grado, por lo tanto, podemos descifrar que lo que anteriormente era un trabajo final de carrera (Universidad de La Laguna, julio de 2015) se ha transformado en lo que pretende ser un artículo de investigación, rebasando los límites del espacio y la estructura exigidos.

Previo a adentrarnos en materia es necesario recalcar que en esta partida, juego con ventaja, ya que no hay estudios previos que se dediquen a exponer la presentación de un personaje en los media, por lo tanto la idea a intentar plasmar será novedosa en la materia de las ciencias sociales y otras ramas de conocimiento que verán nuevos nichos de intervención. La intención es elaborar un proyecto que permita afrontar el análisis de cualquier personaje en su totalidad, aunque se deba tener en cuenta los matices de cada uno de ellos. Un objetivo que va más allá de lo propuesto pero que se podría relanzar como sucesorio a partir de la realización de este estudio.

La idea primordial era la de elegir un personaje que cubriese un amplio espacio en los medios de comunicación, y por ello desfilaron por la pasarela desde Francisco Nicolás (el pequeño), mi segunda opción Esperanza Aguirre, jugadores de fútbol, el ahora rey Felipe VI, e incluso, la popular princesa del pueblo, Belén Esteban. Por parte del tutor ${ }^{1}$ se me propuso que la elección en cuestión, se basara en el tipo de "respuestas emocionales" que suscitara en mí el personaje, lo que se denomina "caer mal" o "caer bien", que me produjera rabia o por contrapartida me origine cierto aprecio, inada más lejos!, preferí por

\footnotetext{
${ }^{1}$ Mis mayores agradecimientos a "anónimo".
} 
decantarme por un personaje neutro, que pudiese estudiar lo máximo posible de manera objetiva.

Otro de los puntos clave en la adopción es afrontar el cómo vas a analizar el personaje, ya que por el espacio material disponible se saldría del límite abordar la presentación del personaje tanto en la "caja tonta" como en los transistores, computadores y otros tantos medios, apuesto por concretar en los medios de comunicación que informan a partir de la escritura, es decir, la prensa, siendo más factible acotar el trabajo en un tipo concreto de medio, no imposibilitando una ampliación en tiempos futuros.

\section{Metodología:}

En cuanto al segundo apartado fundamental en todo artículo (aquél que el corrector, tribunal, profesor, tutor o analista busca como si de Wally se tratase) es el que concierne a la tan polémica, en el ámbito académico, metodología. Y aprovechando que pasamos por el Pisuerga, la pregunta esencial, ¿cuál es el objeto de estudio de este trabajo? Lo primero es mostrar los entresijos de un personaje en concreto, es decir, si tuviera que relatar esto como objetivo central sería: analizar durante el último cuatrimestre del año 2014 (de septiembre a diciembre, éstos inclusive) la presentación y producción que exhibe la prensa escrita sobre la actual Reina del Estado español, Letizia Ortiz. Obviamente, no debo ser conservador ni conformista, he de ir más allá y plantear otros subobjetivos que se me puedan ocurrir, tales como elaborar un primer marco de análisis de un modelo poliédrico o sentar las bases de una confluencia más amena entre los estudios culturales y la economía política. Y no lo digo yo. Douglas Kellner expone tanto en "Economía política y estudios culturales" como en "Cultura mediática" la disputa entre los dos enfoques y por ello, pretende esbozar unos estudios culturales que define multiperspectivos, proponiendo un único enfoque transdisciplinarios en el que converjan tanto unos como los otros. Sin asentar conocimientos sobre las dos escuelas, centro el marco de actuación, los estudios culturales abogan por un enfoque textual, rescatando el análisis de textos por artefactos culturales, partiendo de lo que denominamos por un análisis cualitativo mientras que por el contrario, y según presenta D. Kellner los métodos de la economía política se basan en la investigación estructural, a partir de una visión macro, la que se presenta por medio del análisis cuantitativo, unos datos que se obtienen por medio de fuentes secundarias elaboradas por las auditorías de medios.

Por lo tanto, a partir del examen riguroso de los textos junto con la observación del impacto de las audiencias, es decir, desde las perspectivas de los estudios culturales y la economía política, se me permitirá ahondar en materia. En otras palabras, Kellner destaca que "la cultura de los medios ha conseguido dominar la vida cotidiana" (de ahí el título académico), afirmando además que "la cultura mediática es un terreno contestatario que grupos sociales clave y las ideologías política contrapuestas luchan por dominar, que los individuos viven de estas luchas a través de las imágenes, discursos, mitos y espectáculos de la cultura 
de los medios" (Kellner, 2011). Por lo tanto, la importancia en este trabajo se debe a que "los textos culturales de los medios no son meros vehículos de ideología dominante, ni entretenimiento puro e inocente. Más bien, son un artefacto complejo que encarna discursos políticos y sociales, cuyos análisis e interpretación requieren métodos de lectura y crítica que articulen su inserción en la economía política, las relaciones sociales y el entorno político en el que son producidos, circula y son recibidos" (Kellner, 2011). Cita clave, si se me permite, que revela la pretensión inicial de este artículo.

\section{Modelo poliédrico:}

Para poder entender el propósito se ha de comprender qué es un personaje, qué es un poliedro y quién es Letizia Ortiz.

En primer lugar, el punto más importante para mis lectores es tratar de explicar lo que defino por personaje. No soy yo, o sí, el que escuchó leer/decir que la sociología es la ciencia que estudia el sociólogo, es decir que un personaje es lo que hace el personaje, ni tampoco el que entendió que la sociología es lo que las demás ramas de conocimiento no pueden ser, eterna discusión entre el ser y el deber ser, por ello, me permito el lujo de exponer que personaje ${ }^{2}$ no es lo mismo que personalidad ${ }^{3}$ o persona ${ }^{4}$. Podemos pasearnos por los pasillos de cualquier de nuestras facultades españolas y podemos encontrar una gran cantidad de lo primero, de lo segundo y de lo tercero, aunque puede parecer que de lo primero abunde en mayor medida más que en otros lugares (he de decir que esto es subjetivo, si se me permite).

En el mundo viven más de 7 mil millones de personas, y cada una de ellas se ha "construido" una personalidad que por ende es propia de cada uno (sigo con las perogrulladas), pero esto no coincide con la naturaleza del concepto de personaje ya que si todos los individuos fueran de distinción no existiría tal, ni tampoco calidad, ni todos podemos ser representantes en la vida pública, o sí (eterno debate político). Ni siquiera podemos apostar por recoger el significado de la RAE, porque nadie en su absoluto juicio conoce a sus representantes políticos a partir del tercer puesto en su circunscripción electoral (es exactamente igual si se trata a nivel local, regional o nacional), tampoco se conoce al del primer puesto, por lo que se ha acotar en mayor medida a los representantes de la vida pública. Se me tachará, por no haber tenido en cuenta que en la vida pública no se refiere solo a la política, cierto, faltan aquellas personas que aparecen en lo que Edmund Burke denominó, a través de la metáfora, el "cuarto poder"5, o lo que se situaba en el punto de mira de la Escuela de Frankfurt ${ }^{6}$, los mass media, los medios de comunicación de masas,

\footnotetext{
${ }^{2}$ Según la RAE: persona de distinción, calidad o representación en la vida pública.

${ }^{3}$ Según la RAE: diferencia individual que constituye a cada persona y la distingue de otra.

${ }_{5}^{4}$ Según la RAE: individuo de la especie humana.

Artículo online: "El final de la metáfora del cuarto poder" disponible en: http://www.unav.es/fcom/communication-society/es/articulo.php?art_id=279

6 Por ejemplo, en "El hombre unidimensional" de H. Marcuse: "nuestros medios de comunicación de masas tienen pocas dificultades para vender los intereses particulares como si fueran los de todos los hombres sensibles" (pág. 8).
} 
al igual que la escuela de los estudios culturales, con los medios de comunicación social ${ }^{7}$.

El conglomerado que forma ese, tan poco tomado en profundidad en la academia, poder, reúne a una serie de instrumentos de comunicación entre los que se encuentran los periódicos y revistas, la radio, la televisión y las actuales "redes sociales", elementos comunicativos que son los que permiten la presentación de un determinado individuo hacia parte del público, es el mecanismo que establece las pautas para darse a conocer, con lo que conlleva todo el proceso de idealización, mitificación y/o repulsa hacia el personaje, todo lo que se esconde detrás de la fama.

Una fama que proviene del latín y que significa "rumor" en la que Francis Bacon en su obra mitográfica "La sabiduría de los antiguos" encuentra una correspondencia entre el relato simbólico y la interpretación del supuesto contenido velado (Manzo, 2013). Del mismo modo que esto nos permite afrontar el análisis del discurso que se explicará y analizará posteriormente, por lo que lo relevante en estas líneas es aclarar que para Bacon la fama se corresponde con la ignorancia, cuyo rostro está cubierto de nubes y narra fábulas. Con esto no quiero decir que en la prensa se rellenen líneas con fábulas (solo hay que dedicar tiempo para corroborar que, en realidad, me equivoco) pero sí que una de mis labores es despejar el mar de nubes que cubren al personaje en las páginas de la prensa escrita.

Pero regresando a la construcción del concepto de personaje, establezco que existe una diferencia de éste con respecto al famoso. He descrito más arriba, que la fama la entiendo como la consecuencia del paso del individuo al famoso por lo que ésta "permite distinguir a ciertos individuos como relevantes entre aquellos que se le parecen" (Busquet, 2012) además centrando el concepto de fama entendido por M. Rivière (2009) como "una construcción comunicativa producida por la interrelación humana y social", distinguiendo la autora tres niveles: el individual, el social y el mediático, en el que los dos primeros según ella abarcan "la construcción de la fama por parte de cada individuo con su entorno más próximo y directo". La vaguedad conceptual no especifica en mayores líneas los tres niveles explicitados en el artículo aunque optaré por concretar en el mediático, es decir el nivel producido en los mass media. Sin embargo, M. Riviére (Busquet, 2012) especifica "La fama interviene en la creación del orden social al transmitir valores morales y jerarquías sociales", por lo que la presencia de la reina Letizia Ortiz en las páginas de la hemeroteca virtual se ojeará con lupa.

J. Busquet distingue tres tipos de fama presentes: los que ocupan cargos de representatividad pública, conformando lo que Wright Mills definiría como una élite del poder $^{8}$, que tienen la capacidad de influir en las decisiones de la

\footnotetext{
${ }^{7}$ A partir de la obra de Raymond Williams, "Los medios de comunicación social" (2013): "El desarrollo de poderosos medios de comunicación nuevos ha coincidido [...] con la difusión de la democracia y los intentos, por parte de diversos grupos de dirigentes, de controlarla y dirigirla".

${ }^{8}$ Callejo, (2000, pág. 8) cita a Wright Mills (1975, pág. 11) en "La élite del poder": "No todos los hombres son corrientes u ordinarios en este sentido [...] algunos individuos llegan a ocupar posiciones en la sociedad norteamericana desde las cuales pueden mirar por encima del
} 
comunidad; los primeros ceden la primera línea de protagonismo a la "élite del éxito social", que destacan en los distintos campos del deporte, arte, ciencia y el espectáculo pudiendo convertirse en modelos de referencia; y por último, el tercer tipo de personajes que son los "normales", personas conocidas por su presencia constante en los medios de comunicación, lo que Busquet denomina "fama igualitaria" que es la que permite que cualquier persona puede ser famoso sin realizar nada extraordinario.

A partir de esta tipología presentada aparecen dudas que no han sido resueltas en la lectura del sociólogo catalán. Si retomo que Busquet (2012) define la fama como "un instrumento imprescindible para entender la dinámica de los individuos socialmente excelsos que hoy compiten en el mercado del interés público creado por la realidad mediática", destaco que no todos los tipos de fama compiten por ocupar un espacio en los medios de comunicación. De modo similar, estipula que el tipo de fama coincide con la personalidad, y eso simplemente a partir de la definición de la RAE queda totalmente fuera de lugar, es decir, el concepto de fama lo utiliza a su convenio, destacando que en la tipología de fama existen en el mismo marco tanto personalidades, en el primer arquetipo, la élite del poder; como personajes, conforman la "élite del éxito social"; y las personas, aglutinadas en la "fama igualitaria".

Nada más lejos de la realidad, en los tres prototipos (que espero que no sean tipos ideales) podemos encontrarnos tanto a personas como a sus respectivas personalidades, una personalidad política no puede vivir sin su persona, al igual sucede con respecto a los personajes de la "élite del éxito social" y los de la "fama igualitaria" que requieren de su persona y su personalidad. ¿Acaso solo se puede considerar que los que aglutinan "la élite del éxito social" son los artistas, deportistas, científicos, y los del espectáculo? ¿No es un éxito social ser una personalidad política o un efímero famoso como distingue Busquet? ¿Y por qué a los políticos se les trata de personalidad? No entraré en la definición del éxito social, porque habría que considerar quién produce lo que es éxito y lo que no, y qué es lo que hay que considerar ser exitoso. Si tenemos en cuenta, que la sociedad en la que vivimos es la "virtual" y que el éxito se consigue a partir de tener un $X$ número de retweet o ser trending topic se nos influye de que cualquiera tiene la libertad y la posibilidad de ser exitoso, pero no es correcto definir famoso en cuanto posees éxito ya que chocaría con la gran cantidad de faranduleros que se venden como mercancías depresivas, aireando sus pasados y presentes además de sus "piojos en la cabeza" (cual miseria). Los que coloquialmente se les denomina por "vivir del cuento".

Me basaré en un modelo que permita concretar el concepto de personaje y diferenciarlo con el de famoso, consideramos que el famoso es aquél que es un profesional de la fama, que vive de ella, tanto parcialmente como totalmente. Es decir dentro de éste concepto se puede subdividir en tres subgrupos: entre los que únicamente sobreviven siendo visibles dentro de los medios de comunicación, por ejemplo los participantes del programa televisivo de la parrilla "Mujeres, Hombres y Viceversa", que cobran por cada participación en un capítulo del mismo. El segundo grupo subdivido son los que coexisten, tanto a partir de realizar una labor definida como de nutrirse por medio de la

hombro [...] y con sus decisiones pueden afectar poderosamente los mundos cotidianos de los hombres y las mujeres corrientes" 
producción de sí mismo, por ejemplo la cantante colombiana Shakira, cobra por todo lo que rodea a la fábrica de su música al igual que se le reconoce por publicar su vida privada en la "prensa rosa". Este segundo subgrupo está a caballo entre lo que tomaré por famoso y personaje. Y por último, el tercero, está formado por aquellos que no son famosos pero que son relativamente "palpables" al ser leídos, escuchados, vistos en los medios de comunicación. Estos mantienen un estrecho margen entre su vida pública y vida privada, siendo exclusivamente conocidos por su presencia en los medios, por ejemplo, el presentador del tiempo en la cadena privada Antena 3, Roberto Brasero.

Por ello, se ha de aclarar que el estudio de esta tipología, se corresponde solo a un análisis de un personaje poliédrico que no es lo mismo que personaje literario. Es decir, para poder realizar un estudio en este ámbito específico el cuadro quedaría de la siguiente manera (empezando de izquierda a derecha): el primer grupo estaría formado por los "profesionales mediáticos", viven de su profesión cercana al medio de comunicación; el segundo son los personajes "celebridades y profesionales", que confluyen en ellos la fama y la profesión; y en el tercero, los "famosos profesionales", solamente se aprovechan de su fama. Todos ellos, están en la punta de lanza de cualquier trabajo que intente abordar el personaje poliédrico, pero antes de esto se ha de vislumbrar lo que significa poliedro.

Un poliedro lo descifro como una superficie plana tridimensional en un espacio que no es infinito, es decir, que la determinación es colocar al personaje escogido dentro del poliedro y removerlo como si fuese una lavadora que nos proporciona limpieza, suavidad (dependiendo del suavizante) y ahorro temporal, lo que en estos términos académicos se relata en una única palabra, resultados de estudio. Por consiguiente, el personaje poliédrico es aquél que puede ser introducido dentro de la superficie y abordar las perspectivas y los matices de este tipo de investigación, un personaje que no debe ser de ficción sino que constituya lo que Rivière señala por personaje mediático (Busquet, 2012), éste "transformado en icono y celebridad actúa como un símbolo: es embajador de valores y modelos sociales y creador de opinión en todos los terrenos -desde la estética hasta la ética-." Sin embargo, aunque no se establezca claramente lo que se define por icono y celebridad, sí que cualquier personaje actúa simbólicamente en el plano, tanto creando opiniones como a su vez aprovechando la posición de los medios para producir su imagen a partir del personaje fomentando ciertos valores y creencias. Al igual sucede por parte del público, que es quién decodifica el mensaje a partir de lo que ve o lee. Ello, es lo que Stuart Hall intenta asentar en su análisis "Codificar/Decodificar" planteando desde un principio tres modelos que forman parte de la investigación en las comunicaciones masivas. El tradicional es el criticado por su linealidad, como resalta Hall, que se basa en el emisor, mensaje y receptor. Por otra parte, también presenta la "compleja estructura de dominación" que se corresponde con la producción, circulación, distribución/consumo y reproducción, un modelo que se aproxima a la versión marxista, y que como destaca S. Hall se presentaría por producción-distribución-consumo-producción trazando un circuito continuo (Martín Cabello, 2008). Sin embargo, sin abarcar mucho más los planteamientos de $\mathrm{S}$. Hall, sí que me gustaría revisar estos modelos en un análisis poliédrico sobre un personaje en concreto. 
La importancia del poliedro (Cuadro 1) es tener en cuenta las perspectivas del productor de la noticia, tanto sea el medio de comunicación, el grupo con el capital que decide las informaciones a publicar como aquél que la redacta que es el periodista. El otro foco de atención al respecto, y es el último del ciclo es el receptor, el público al que le llega la información y la interpreta. Y por último, el polo que está en medio lo interpretaré como el canal, que es el elemento que traslada la noticia desde el periodista hasta el lector o televidente, en el que se incluye tanto la forma y la estructura del mensaje hasta el soporte del mismo. Dentro de cada polo, como aparece en el cuadro 1, se subvierten distintas lógicas de actuación. En el lado "A", aparecen la disputa entre el productor y el periodista, las diferencias de posiciones y quién posee en definitiva la última palabra mientras que en el lado " $C$ " aparece las perspectivas de la percepción y decodificación del mensaje. Éste debe tener en cuenta la tipología periodística además de los debates entre los géneros (la cada vez menos nítida diferenciación entre información, interpretación y opinión): "según la información con la que se cuente será más apropiado un género que otro, pero también según el género elegido será necesario o no buscar más información" (Paniagua, 2009). Por último, en el lado "B" se adopta la observación tanto de los significantes y la sintaxis de las informaciones hasta los significados, el contexto e incluso el estilo de la publicación. No me debo de olvidar del lado "d" es la cara en la posición paralela al plano $X$ en el espacio que es el que sostiene la personalidad real, oculta del personaje que no siempre tiene que coincidir con la que se presenta en los medios de comunicación.

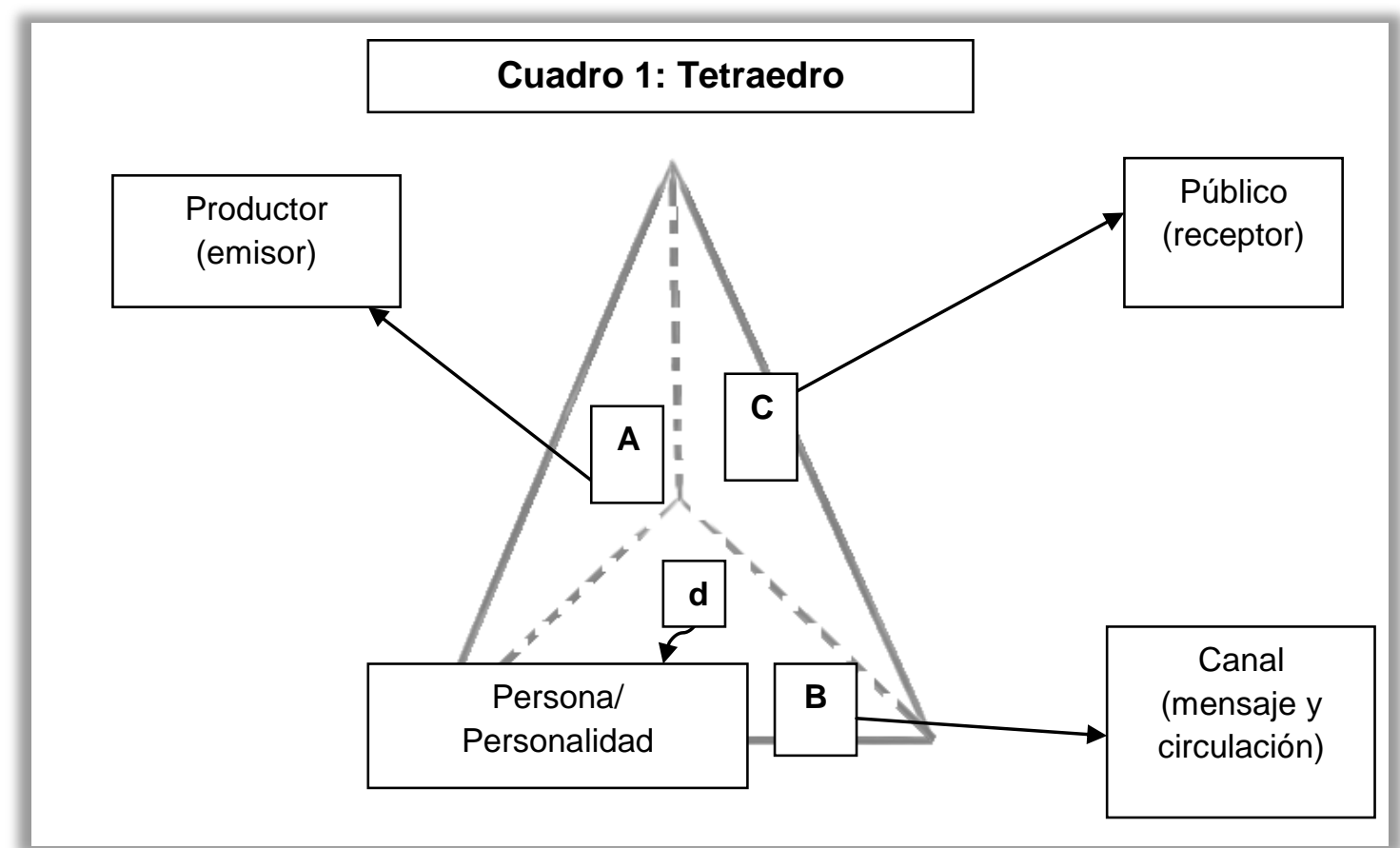

¿Quién es Letizia Ortiz? puede que no la conozcan pero es la actual reina de la corona española, nacida en Oviedo en 1972, hija de Jesús Ortiz Álvarez y Paloma Rocasolano Rodríguez. La Reina es licenciada en ciencias de la información en la Universidad Complutense de Madrid, realizando un máster en Periodismo Audiovisual. Cumplimentó la práctica laboral en $A B C$ y La Nueva España, además de trabajar en la agencia de noticias EFE. Antes de ser reconocida a nivel nacional como la futura reina desempeñó una trayectoria 
televisiva comenzando en la sede madrileña de la cadena Bloomberg al igual que en el canal privado $C N N+$ hasta su incorporación a principios de milenio en Televisión Española, donde se le comenzó a conocer en la pequeña pantalla por ser presentadora de los informativos en la segunda edición del telediario ${ }^{9}$. Se ha de señalar la importancia de que un estudio poliédrico no consiste en realizar un trabajo biográfico, siendo necesario recoger parte del contexto personal del personaje escogido. Hay dos elementos personales clave en el estudio sobre Letizia Ortiz, el primero de ellos es que como se puede comprobar, proviene de una familia no aristocrática, y el segundo, es lo relativo al periodo previo a contraer matrimonio con el actual rey Felipe VI en el 2004, la periodista se había comprometido con otra persona en 1999, elementos fundamentales que seguramente darán de que hablar en las páginas de la prensa escogida. En cierto modo, faltaría concretar el tipo de personaje con el que clasificaré a Letizia Ortiz, debido a que por medio de la Corona, cumple un papel simbólico de representación de la nación española, al igual que su anterior profesión de periodista, se ha de situar como un personaje "profesional no famoso".

\section{Productores y periodistas:}

En el primer eslabón del estudio poliédrico nos encontramos con los productores del personaje que en este caso aglutinan a todos los medios de comunicación. Por falta de accesibilidad y por imposibilidad material para trabajar toda la fabricación de noticias, artículos, crónicas y demás géneros periodísticos me centraré tanto en las revistas como en los diarios, debido a su facilidad en el manejo del estudio, optando por las hemerotecas digitales.

Uno de los difíciles dilemas es elegir los periódicos y revista, además de la cantidad de los mismos inclusive teniendo en cuenta el período de análisis más la justificación de ello. Por lo tanto, en busca de la última objeción tuve que recordar la importancia de destacar el personaje en los distintos "panfletos" existentes, tanto por revista o por periódico, posibilitando presentar el personaje en todos los ámbitos. Es decir, es necesario acotar un tiempo ajustado, apostando por el último cuatrimestre del año anterior poscoronación y comienzo del primer curso laboral para la nueva pareja de reyes hasta la finalización del año, me refiero desde septiembre hasta diciembre del 2014. ¿Qué publicaciones en concreto? La importancia en mantener la continuidad en el estudio poliédrico nos obliga a apostar por medios que sean absolutamente amplios en la producción de informaciones sobre Letizia Ortiz y a su vez que sean convenientemente ojeados por parte de la población. Para ello, qué mejor que acceder a la AIMC (Asociación para la Investigación de Medios de Comunicación) en su página de Internet y fijar la vista tanto en el marco general de medios en España ${ }^{10}$ al igual que en el resumen general anual $^{11}$, posibilitándonos, previamente a la observación de los datos, la capacidad de obtener resultados que nos proporcione un camino en la aceptación de uno u otro diario, atendiendo tanto a los periódicos de tirada

\footnotetext{
${ }^{9}$ Información proporcionada por la página web de la Casa Real.

${ }^{10}$ La AIMC presenta esta publicación a partir de la EGD (Encuesta General de Medios).

${ }^{11}$ Resumen General del 2014 (de febrero a noviembre).
} 
diaria como a las revistas semanales. En consecuencia destacamos del resumen general anual lo siguiente: en cuanto a las revistas semanales la clasificación está copada por Pronto con 3,4 millones de lectores, seguida por Hola con 2,3 millones y en tercer lugar Lecturas con 1.390.000. Destaco que el informe no precisa a que se refiere con lector aunque supongo que contabiliza por revista vendida como lector aunque no sea precisamente así, al igual que tampoco especifica la tirada de cada medio. Por otra parte, es de señalar que incluso las tres primeras revistas del ranking son las que forman parte del conglomerado definido por "prensa rosa", que se dedica a publicar en sus páginas la vida tanto pública como privada de las personas famosas, aunque se incluyan otras informaciones relativas a la cocina, el horóscopo, salud,... Con respecto a los diarios en el resumen general anual, nos encontramos en primer lugar a un periódico que no es generalista sino de materia específica al ser deportivo, el Marca, donde llega casi a doblar en número de lectores al siguiente medio impreso dedicado a las informaciones deportivas. En el siguiente puesto de la lista aparece la primera de las coloquialmente denominadas publicaciones serias (como si las demás fueran broma), El País con una cifra de 1.600 .000 lectores. El ranking lo continúa As con 300 mil lectores menos que El País y El Mundo es el segundo periódico generalista en una cifra un poco superior al millón y en el quinto puesto aparece en la lista el primer diario que actualmente trata informaciones en ámbito regional, La Vanguardia, cerca de los 700.000 diarios vendidos. No obstante, es conocida la tendencia monárquica de algún boletín en concreto, ya que sus informaciones sobre la Casa Real abundan con respecto a otros rotativos y ése es el $A B C$ rozando la cantidad del medio millón de periódicos vendidos y/o lectores al día.

Sin embargo, se ha de hacer un pequeño apunte. Debido a la decisión previa de escoger revistas con publicación online habría que observar la clasificación de los dominios virtuales, ya que no tendría por qué coincidir las entradas en las páginas virtuales de los distintos medios con la cantidad de publicaciones vendidas en formato papel. Además de esto, es importante señalar que la AIMC no tiene integrada en su totalidad todos los medios disponibles que publican en el territorio nacional, por ello se ha de tener en cuenta el margen de error en el análisis. Los informes de la AIMC (nos aportan los datos tanto del resumen anual como de la tercera y última ola octubre/noviembre del 2014) nos revelan que el sitio en Internet más visitado sin duda es Youtube, en el que según el marco general copa el $52,7 \%$ de todos el espacio online en España que como indica el resumen general del 2014 "alberga" 20,9 millones de visitantes únicos en 30 días, dato escalofriante si tenemos en cuenta que la población española no supera los 47 millones de habitantes. Sin duda alguna el canal de vídeos Youtube es la actual plataforma predominante, escenario en el que se producen los nuevos famosos populares tales como "elrubiusOMG" 12 , "TheWillyrex" ${ }^{13}$ y "loulogio"14. En cifras más "corrientes" nos encontramos con Marca.com y Elpaís.com, siendo visitada cada web alrededor de 5 millones en

\footnotetext{
${ }^{12}$ Es el youtuber con más suscritos en España, con una cantidad de 12.326.121.

13 En su portal aparecen registrados 7.129.159, su vídeo más visto se ha reproducido más de 20 millones de veces.

14 Aunque muchas otras personas le superan en visualizaciones y en suscritos a su página personal es uno de los que más repercusiones ha tenido en la televisión. Aparecen registrados poco más de medio millón de usuarios de Youtube.
} 
30 días. Sin detenerme en toda la amplia clasificación de las diversas páginas, fijo la atención en que $A B C$.es se convierte en el segundo periódico generalista con más visitantes únicos, solo adelantado por Elpaís.com (y sin tener en cuenta 20minutos.es ya que solo publica en versión online) con una cantidad bastante inferior que se sitúa en 1.660 .000 visitantes $^{15}$. Continuando, en la clasificación la siguiente revista que aparece es Hola.com que abarca un $1 \%$ de la audiencia en Internet según el marco general, que se plasma según el resumen anual en 391.000 visitantes únicos en un mes.

A partir de estos datos relevantes espero no equivocarme con la elección que permita, o al menos no impida, un correcto y relevante análisis textual del personaje en los siguientes medios: El País ${ }^{16}$, por ser el diario con carácter generalista con mayor tirada a nivel nacional; $A B C^{17}$, por su condición pro monárquico además de tener la segunda página online más visitada de un periódico no exclusivamente deportivo; y en cuanto al plano de la "prensa rosa" la preferencia, la revista ${ }_{i} \mathrm{Hola}^{18}$, que mayoritariamente recaba informaciones de las Casas Reales (con su sección exclusiva) y ser el primer portal en Internet en el sector de las revistas semanales. Cabe señalar, el no haber escogido la revista Pronto, la de mayor cantidad de ventas en impreso, porque no recoge en una sección la hemeroteca digital, imposibilitando realizar afrontar un análisis de los textos que mencionen a Letizia Ortiz.

\footnotetext{
${ }^{15}$ El caso parecido sucede en las páginas en red de las revistas semanales, la más visitada es la polémica Eljueves.es aunque con el supuesto desmantelamiento es posible la pérdida de lectores. Noticia en El Mundo disponible en: http://www.elmundo.es/television/2014/06/07/53921359ca47412e438b456b.html.
}

${ }^{16}$ El diario más leído de España, solo por detrás de Marca, aunque éste es únicamente deportivo, es El País. Éste, forma parte de uno de los grupos estableshiment más importantes del Estado que es el grupo PRISA que abarca medios como Los 40 Principales, Cadena Ser, AS, Cinco Días, entre otros. La disputa de los dos diarios más leídos se desplaza al ámbito online en el que en Facebook el periódico deportivo le gana la partida con 3 millones y poco más de un cuarto de otro millón de "Me gusta" mientras que El País pasa a poco más de la mitad del deportivo; en cambio, en Twitter se da la "vuelta a la tortilla", Marca mantiene casi la misma cantidad aunque supera a la otra red social, mientras que El País no solo aumenta sino que se multiplican casi por tres a alcanzando los casi 4 millones y medio de seguidores

${ }^{17}$ El diario $A B C$ fue fundado en 1903 por Torcuato Luca de Tena, caracterizándose por ser un periódico conservador, monárquico y católico (López de Maturana, 2005). Después de mantenerse durante los conflictos del primer tercio del siglo XX, cambia de manos en la Guerra Civil a los republicanos, siendo finalmente adoptado por el franquismo imponiendo un director distinto a los antiguos propietarios, hasta que al final de los 40 años de dictadura pasa a ser dirigido por el reconocido periodista Luis María Ansón. Si comprobamos que en el organigrama del diario se mantiene como presidenta editora Catalina Luca de Tena, heredera del fundador, podemos suponer el mantenimiento de la línea ideológica desde principios del s. XX.

${ }^{18}$ Pertenece a la empresa Hola S. L. y que además se encarga de las labores de edición. La revista mantiene su control de la difusión por medio de OJD (Oficina de Justificación de la Difusión) ${ }^{18}$, que a su vez define a ¡Hola! como una publicación de categorización "femeninas" y con una periodicidad semanal, cada adquisición de ésta requiere de un pago de $2 €$. Según los datos aportados por el buscador de publicaciones de OJD, el promedio de la tirada en el 2013 fue de 533.506 mientras que la difusión fue de 399.007. En el 2014, la venta de la revista baja hasta los 386.219 ejemplares al igual que sucede en el promedio de la tirada que también

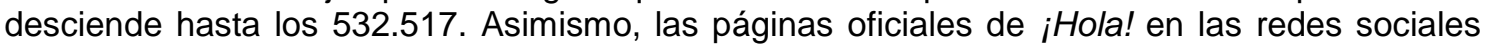
alcanza en Twitter 1.250 .000 seguidores, siendo superada esta cifra en Facebook obteniendo más de 3 millones de "me gusta". 
No se me ha olvidado el otro plato fuerte en la producción de las noticias en la prensa, televisión, radio, "redes sociales" y demás medios, los periodistas. "Es periodista quien trabaja para un medio de comunicación, con independencia de su titulación [...] Es el medio el que les designa como periodistas, el que les da parte de su poder para que lo gestione" (Callejo, 2000). Como resalta J. Callejo el periodista es lo que es por el medio en el que trabaja y por la disponibilidad de material accesible por ello "se les reconoce cierta capacidad de maniobra en el proceso de producción y distribución de los mensajes. Son los encargados de poner las manos sobre los mensajes" (Callejo, 2000). Un papel que saben que interpretan dentro del poliedro y que la misma Reina Letizia Ortiz resalta ${ }^{19}$.

\section{Análisis de texto:}

Supongamos que necesito un conector para comenzar un apartado, en realidad el apartado, ése que conlleva la responsabilidad de producir el correcto artículo de investigación. No puede ser un conector al azar sino que debe estar a la altura que todo personaje merece y mucho más si es una reina (o Reina). Creo que lo he encontrado. Érase una vez que se era ${ }^{20}$ una periodista que trabajaba, después de tantos vuelcos en su vida laboral, en el telediario de la segunda edición de TVE (Televisión Española). Ella recordaba, cuando se preparaba para comenzar a leer el teleprompter ${ }^{21}$, sus andanzas por aquellos pueblos del Oviedo de la Transición, hasta, quién se lo diría, llegar a convertirse en profesional del periodismo. Una reina que vivió en una época muy feliz (o no tanta) hasta que se cubrió de nubarrones el cielo y el Reino entró en crisis, convirtiéndose en la reina austera. Nunca imaginó que aquellos a los que trataba de compañeras/os terminarían narrando sus hazañas en $A B C, E I$ País o en la revista Hola ${ }^{22}$. Unos medios que la iban a construir como "la reina no reina", la reina "acompañante" de la verdadera monarquía (o Monarquía). La dudosa princesa, primero, y reina, posterior, nunca imaginó que iba a ser citada tantas veces, que formara parte del grupo de "Los Reyes" o que la nombraran algunas deportistas, el mismísimo Papa u otras tantas personalidades (que no me refiero a personajes). Con esto, el narrador (en este caso no es omnisciente) desvela que en las 312 noticias encontradas en total, no siempre

\footnotetext{
${ }^{19}$ Noticia publicada en los tres medios, pero destaca del Hola.com del día 15 de septiembre del 2014: "Doña Letizia dedicó un pertinaz elogio a esos periodistas "que siguen creyendo en el periodismo, en la crónica reposada y analítica [...] siempre necesitaremos a esa persona inteligente y responsable que analice, interprete y sintetice en un puñado de palabras, imágenes, sonidos, esas cosas que pasan. Y eso sólo lo puede hacer un buen periodista"."

${ }^{20}$ Se podría interpretar que tantos comienzos no llevan a un final, pero se debe a la imposición estructural dividido en apartados, impidiendo escribir un relato.

${ }^{21}$ Se refiere al también denominado autocue, aparato que permite a los presentadores de la televisión leer lo que escriben los guionistas o periodistas (no buscar en la RAE).

${ }^{22}$ Se refiere a los cálculos y filtros realizados en las tres hemerotecas digitales del último cuatrimestre del 2014. En la página web Hola.com se publicaron 65 noticias (se han desechado las fotos o videogalerías): 13 correspondientes al mes de Septiembre, 30 a Octubre, 12 en Noviembre y 8 en Diciembre. Respecto a $A B C$.es, se supera la cifra del medio anterior y aglutina 206 informaciones en todo el período: 55 en Septiembre, 71 noticias en Octubre (el mes más productor sobre Letizia Ortiz en los tres boletines), en Noviembre 34, y en Diciembre se llega a la cifra de 46 noticias. Por último, en cuanto a EIPaís.es en Septiembre se publican 11 , Octubre es la mayor cantidad, superando por una noticia al mes anterior, en Noviembre se alcanzan las 9 , y en Diciembre se mantiene en 9 informaciones.
} 
aparece el trato en particular a la Reina Letizia Ortiz, sino que el personaje, en la gran mayoría, se construye a partir de la categoría "Reyes", apareciendo en las noticias dentro de la pareja formada con Felipe VI. Por lo tanto, el único criterio de selección en el buscador de las respectivas hemerotecas era fechar el período entre Septiembre y Diciembre del 2014 y "apuntalar" en palabras a buscar: Letizia Ortiz.

No creo que le hiciese mucha gracia, a la actual Reina, formar parte del conglomerado "Reyes" y menos si se le expone en público a lo que denomino polémicamente como "fiel acompañanta" (añado fiel). Porque no es que solo se represente así sino que en las páginas, en alguna ocasión, se le destaque de esa manera incluso cuando no "acompaña" al Rey. Debe ser la acompañante de Felipe VI como la acompañada por otras personalidades, dándose el extraño caso, en el que, o los periodistas solo saben conjugar el verbo acompañar, o es delito de Estado que no pudiera tener intimidad en ningún momento ${ }^{23}$. ¿Y por qué esta retahíla del acompañamiento? Como revelé, "hace un par de líneas", la gran mayoría de noticias en las que aparece Letizia Ortiz se supedita a la palabra "Reyes" ${ }^{24}$, anteponiéndose al personaje de la Reina, Felipe VI. Esto nos muestra que el personaje está subordinado al jefe de Estado que es el Rey, por lo que la generalidad de noticias producidas y presentadas, muestra la labor de la monarquía simbolizada únicamente en Felipe VI, mientras que a Letizia Ortiz se la relega a un segundo plano, lo que ofrezco como "acompañante".

Sin embargo, el papel de Letizia recuerda más a aquella señora que representaba a la Segunda República, recordemos el traje blanco que vestía, junto a la bandera tricolor de fondo. Unos trajes y unos colores que no son

${ }^{23}$ En Hola.com: “...doña Letizia siempre había acudido acompañando al príncipe Felipe....; "EI Rey ha sido uno de los primeros oradores de la Asamblea General con un discurso pronunciado poco después de que tomase la palabra el presidente de Estados Unidos [...], acompañado por doña Letizia."; "...el rey Felipe y el gran duque Enrique han pasado revista a las tropas, mientras el príncipe Guillermo acompañaba a doña Letizia."

En ABC.es: "El miércoles será Felipe VI quien, acompañado de Doña Letizia...”; “...el Rey viajó acompañado de la Reina a Santiago de Compostela..."; "Doña Letizia viajó a Marín esta mañana para acompañar a Don Felipe en los actos centrales de la Academia Naval Militar..." ; "...el Rey no estará acompañado por su padre, pero sí por la Reina Letizia."; "En la visita ha estado acompañada por la esposa del presidente de la República Portuguesa, María Cavaco Silva,..."; "Acompañado de Doña Letizia, el Rey ha llegado a Berlín a las 11.45 desde Madrid para dirigirse al Palacio Bellevue,..."; "...el Rey ha confesado que su esposa, la Reina Letizia, se había quedado "con ganas» de acompañarle en esta Cumbre Iberoamericana."

En EIPaís.es: "Doña Letizia no quiso más celebraciones públicas que este almuerzo rodeado de colegas. Tampoco hizo, como en otras ocasiones, posados para la ocasión. Mañana acompaña a don Felipe a Ourense...": "La Reina ha llegado al teatro acompañada de la ministra de Sanidad, Ana Mato,...".

${ }^{24}$ De las 65 noticias en Hola.com, 19 abarcan el género "Reyes", en ABC.es 99 de las 206 tratan a Letizia junto al Rey y en ElPaís.es 21 noticias de 41. Mientras que por el contrario, la presentación de la Reina dedicándole un espacio o se trata en toda la noticia al personaje corresponde a lo siguiente: en Hola.com 33 noticias de 65 (cerca del 50\%), en ABC.es 79 informaciones única sobre Letizia Ortiz de 206 y en cuanto a EIPaís.es 18 noticias exclusivas sobre la Reina, de 41. A partir de estos simples datos, podemos comprobar la diferencia de los dos medios, que por excelencia tratan sobre la Casa Real, en cuanto a la presentación de la Reina, Hola.com personaliza y multiplica las publicaciones sobre ella mientras que $A B C$ la engloba dentro del marco nominal "Reyes". Nota: el resto de noticias que no aparecen en los cálculos, solamente alude el nombre de Letizia, sin más aportación que el significante. 
precisamente los que utiliza en los distintos eventos el personaje, jfaltaría más! (alguno pondría el "grito en el cielo"), pero que son, sin lugar a dudas, lo que determina si lo está haciendo bien o no, me refiero a su atuendo ${ }^{25}$. La moda es lo que debe encarnar Letizia, junto al turismo y la marca España proclama Almudena Martínez-Fornés, que es la apadrinadora de las críticas (también elabora contradicciones ${ }^{26}$ ) hacia la Reina en el periódico $A B C$, una periodista, junto a María Luisa Funes que se dedica a publicar las noticias relacionadas con la Casa Real.

Volviendo al relato, ella, tampoco se imaginó que se le mirara con lupa, los gestos, la vestimenta, sus cortes de pelo. Pero se equivocó, desde el mismo noviembre del $2003^{27}$, hasta estos días, se escribían, los ya antepasados "ríos de tinta", páginas de su personaje fijando la atención únicamente, en lo que incumbe a la prensa, que es su vestimenta. La perfecta comparación la podemos encontrar en el cuento "La Cenicienta", no me refiero a que fuese una muchacha que trabajara en la denominación antigua y machista, labores del hogar, o que quisiese visitar la fiesta de palacio "a toda costa", sino que pareciera que hay que encontrarle constantemente el zapato de cristal perfecto, ardua tarea para cualquier sastre. Infinitas informaciones narran las elecciones de prenda por parte de Letizia para los viajes, reuniones, recepciones e inauguraciones ${ }^{28}$.

\footnotetext{
${ }^{25}$ En $A B C$.es: "Desde que empezó el nuevo Reinado, Doña Letizia no ha cometido fallos. Las pocas críticas que ha recibido se han referido a su forma de vestir."; "...el principal reto que afronta Doña Letizia es construirse una imagen de Reina consorte que sea valorada positivamente por los españoles [...] tendrá que procurar que se hable más de lo que hace que de cómo se viste, un problema que arrastra de sus tiempos de Princesa, cuando empezó a lucir prendas arriesgadas que suscitan críticas y eclipsan su labor."

${ }^{26}$ Se refiere: "La Constitución no atribuye a la Reina ninguna función [...] pero con sus gestos y su labor institucional las Consortes pueden realizar importantes aportaciones a la Corona y a su país, como hizo Doña Sofía en los 39 años del anterior Reinado"; "Doña Letizia tendrá que procurar que se hable más de lo que hace que de cómo se viste"; "Doña Letizia irá sumando a la actividad habitual que desarrollaba como Princesa de Asturias algunas de las funciones que habitualmente realizaba Doña Sofía". Si la Reina no tiene ninguna función, Doña Sofía no podía ejercerlas, por lo tanto Doña Letizia no podrá hacer más que vestir, y la prensa seguirá hablando de su vestimenta.

${ }^{27}$ Se refiere al mes en el que se oficializa el compromiso entre la periodista Letizia Ortiz y el futuro heredero de la Corona, Felipe de Borbón.

${ }^{28}$ En Hola.com: "la reina Letizia que de nuevo acaparó todas las miradas con uno de sus vestidos más atrevidos y favorecedores [...], parece un clásico 'LBD', pero la sorpresa viene al ver la parte trasera, pues deja al descubierto la espalda de la Reina. Es un vestido realizado en seda negra que presenta la espalda en tul con motivos florales bordados. [...] Doña Letizia ha llevado unas originales sandalias negras, clutch a juego y un recogido que dejaba al descubierto los espectaculares pendientes"; "Doña Letizia, que eligió para su primer día en Nueva York un traje de chaqueta y falda burdeos (uno de los colores que más se va a llevar esta temporada), zapatos de tacón de ante en el mismo tono y top crema a juego con su bolso de mano".

En ABC.es: "Doña Letizia acompañó con este original bolso, el conjunto de pantalón negro y jersey blanco con rayas negras haciendo cuadros asimétricos de la marca danesa Designers Remix. En el desfile de la Fiesta Nacional, El vestido de color verde oliva está tejido en tweed y crêpe y lleva como adorno una cremallera central. El modelo, de corte entallado, le llegaba a la Reina por las rodillas. La Reina completaba el «look» con unos zapatos cerrados de tacón alto a juego con el color del vestido y una cartera de mano de tonalidades plateadas. Doña Letizia optó por unos pendientes sencillos de forma alargada y la melena al aire previamente alisada.
} 
Pero no solo las indumentarias de la experiodista rellenan espacio en el historial online, cuenta el narrador, sino polémicas y diferentes palabras entre líneas que desvirtúan la proyección de nuestra Reina. Sin ánimo de caer en el darwinismo social, prefiero destacar la falta de aceptación, todavía en el tiempo, dentro de las informaciones en ABC.es y en Hola.com, por reconocer a Letizia Ortiz como Reina. Conflicto manifiesto si tenemos en cuenta ciertas comparaciones, que se despuntan en estos medios, con otras Reinas ${ }^{29}$ del ámbito europeo, u otras personalidades ${ }^{30}$. Incluso mostrando la falta de "sangre azul" por parte de Letizia, en algunos titulares de Hola.com: "Genes de estilo 'real"', “¿Una auténtica Reina del estilo nace o se hace?”, o el más sorprendente "Y es que doña Letizia no es una Reina típica (la negrita es de la revista)". Eternos recuerdos a su condición de reina (en minúscula), a una mujer que no procede de la realeza, incluso llegados hasta el extremo cuando se publica una noticia sobre el personaje de manera solitaria, sin la compañía de Felipe VI, clasificando la información en el apartado de "Gente\&Estilo" al igual que a su madre, Paloma Rocasolano, mientras que Letizia junto al Rey aparece ordenada la noticia en la sección Casa Real.

En cambio, para la muchacha convertida en Reina no todo debía ser un suplicio, toda moneda tiene su cara (menos el euro), protagonizar el papel de Reina tiene sus más, aparte de estar sometida a la jaula de papel que es la agenda real, puede participar en distintas intervenciones en organismos internacionales o nacionales tales como la cumbre mundial contra el hambre y la nutrición en la Conferencia Internacional sobre Nutrición (de la $\mathrm{FAO}^{31}$, perteneciente a la $\mathrm{ONU}^{32}$ ), además de asistir al II Congreso Iberoamericano de Enfermedades Raras, y entregar el galardón "V de Vida" de la Asociación Española contra el Cáncer (AECC), asociación de la que forma parte al ser vicepresidenta de honor, o acudir a reuniones previstas con la $\mathrm{OMS}^{33}$ y con UNICEF $^{34}$. En estas primeras "mediaciones" en su rol de Reina se puede comprobar la tendencia a caer en el "ongenismo" ya que es una de las únicas funciones, si se puede delimitar como tal, que cumple por ser la que comparte vida con Felipe VI. Lo curioso, es la profundización de la crítica social a instancias supranacionales remarcando problemas mundiales, como el hambre o los conflictos armados, presentando resoluciones que, caen en el idealismo, sin faltar aquella premisa de la "paz en el mundo", olvidando las preocupaciones nacionales en el tintero. No obstante, y es de resaltar, las diferencias en el trato por parte de la prensa en cuanto a $A B C$ y Hola con

En ElPaís.es, en el viaje a Holanda, "...doña Letizia se ha puesto un vestido rojo con flores bordadas del mismo color, del diseñador Felipe Varela. Con zapatos a juego, la única joya eran unos pendientes de brillantes y rubíes".

${ }^{29}$ Titular en $A B C$.es del 24 de Octubre: "Los estilismos de las reina Letizia y Máxima a examen" o el 15 del mismo mes en Hola.com: "Máxima y Letizia: dos estilos 'reales' que coinciden en los Países Bajos".

${ }^{30}$ Como ejemplo el siguiente titular del 31 de Octubre en Hola.com: "El 'duelo' de la reina Letizia y Olivia Palermo", incluso se presenta a debatir a los que usuarios de la página que comentan: ¿Con quién te quedas?.

${ }^{31}$ Las siglas se refieren a: Organización de las Naciones Unidas para la Alimentación y la Agricultura.

${ }^{32}$ Se refiere a la Organización de las Naciones Unidas.

${ }^{33}$ Se refiere a la Organización Mundial de la Salud.

${ }^{34}$ Las siglas representan al Fondo de las Naciones Unidas para la Infancia. 
respecto a El País. En la visita de los Reyes al colegio gallego "Ben-Cho-Shey", en el segundo periódico generalista se presenta la noticia con una manifestación de los representantes del "Ampa" debido a los recortes en educación y a la "LOMCE ${ }^{35}$ ", en cambio en los primeros boletines la información pasa inadvertida, aunque en posteriores días aparezca una publicación en $A B C$.es el que se ensalza la figura de la Reina ya que atendió una petición de una niña, a través de una carta de su madre, en el que se le suplicaba cierta intervención ya que no disponía ni encontraba un empleo. Por lo tanto, en El País.es se muestra lo que cada vez sube más en el indicador de los problemas sociales en el CIS, los problemas de índole social, de manera general a través del "Ampa" del colegio mientras que en $A B C$ se particulariza el problema en un caso aislado.

Retornando a la breve historia, se ha de saber, como ya Letizia ha aprendido, que la persecución de los medios de comunicación puede ser un lastre, pero puede favorecer la transmisión de sus ideas, como la defensa, en un acto de su antiguo gremio, del periodismo de calidad, de la crónica inteligente, de la independencia ideológica, los que protegen la profesión frente a las "noticias exprés", la ligereza en la informaciones, falta de reflexión al escribir, a los que ceden ante las presiones de los superiores. Se presenta en los tres medios de comunicación, a una Letizia Ortiz como pocas veces se le ha visto en las noticias de los cuatro meses, un papel totalmente crítico con el medio, defensora de su anterior vocación, una reina en cuanto a sujeto activo y reflexivo, recordando a los planteamientos de Ulrich Beck sobre la individualización, en algunos momentos se presenta a la Reina tanto sujeto pasivo acompañando a Felipe VI o cumpliendo sus "funciones" de consorte del Rey mientras que en otros se asume su aportación en las elecciones de los vestidos 0 en las opiniones vertidas sobre la defensa del periodismo. Individuación, significa destradicionalización, pero también lo contrario, [...] no es un asunto de solidaridad ni obligación, sino de coexistencia en la contradicción (Beck, U: 2001). ¿Qué mejor contradicción que se presente a Letizia como cumplidora de sus deberes como Reina ${ }^{36}$ al igual que ejercer su papel de solidaria (o caritativa) ${ }^{37}$ ? Incluso se podría percibir que la diferencia se

\footnotetext{
${ }^{35}$ Polémica ley del actual gobierno (a 15 de julio del 2015), Ley Orgánica para la Mejora de la Calidad Educativa (LOMCE). Disponible, su contenido, en: http://www.boe.es/boe/dias/2013/12/10/pdfs/BOE-A-2013-12886.pdf.

${ }^{36}$ Noticia de EIPaís.es, publicada por Inés Chávarri el 17 de septiembre del 2014: "Doña Letizia presidió el acto de entrega de premios y de ayudas de la Asociación Española Contra el Cáncer (AECC). La Reina, presidenta de Honor con carácter permanente de la Asociación, ha sido recibida a las puertas del teatro por varias decenas de curiosos...". Lo mismo sucede en $A B C$.es cumpliendo sus deberes el 20 de noviembre, Pablo Ordaz escribe: "La participación de doña Letizia ante la cumbre de la FAO, a la que asistieron jefes de Gobierno y expertos mundiales en alimentación y agricultura...

${ }^{37}$ Titular de EIPaís.es: "El Sergas (Consejería de Sanidad en Galicia) cita tras mediar la Reina a un niño al que negó tratamiento", reflejándose en el contenido las supuestas intenciones de Letizia en palabras de la madre, "Yo ya me imaginaba que la Reina iba a hacer algo", señala la madre, esperanzada." Rozando la definición del tráfico de influencias al igual que ocurre y se expone en $A B C$.es: "La Casa del Rey ha remitido una carta a una niña malagueña de 12 años que en la última visita de los Reyes a Málaga dio una biznaga y una postal a Doña Letizia, pidiendo que hablara con la presidenta de la Junta de Andalucía, Susana Díaz, para que ésta «le devuelva el trabajo a mi mamá», ya que había sido despedida" o "«Doña Letizia prometió respondernos y así lo hizo».
} 
difumina, pero el juego de roles está presente enseñando a la persona de las dos maneras, dependiendo del contenido y del evento.

Nada más lejos de la realidad, no hay que tomarse al personaje, con aires de grandeza o de súbita arrogancia sino de cercanía, disponibilidad y atención al público. Ella al igual que Felipe VI son personas de carne y hueso que, eso sí, tienen mayor capital económico. Pasando de puntillas, y muy por encima, de los planteamientos bourdianos ${ }^{38}$ podemos entender las prácticas de Letizia Ortiz, en cuanto al campo de la moda, tomando en consideración no solo el capital económico, sino el educativo, cultural, entre otros. Con esto me refiero, a que podemos entender a Letizia como el personaje que debe satisfacer la posición que ocupa al respecto, es decir, efectuar los cánones de las posiciones dominantes en la moda por su papel de Reina. No puede existir una monarca que no establezca distinción entre su puesto de "acompañanta" en la jefatura de Estado y el resto de la población. Si entendemos que el valor de una posición depende del valor de las demás colocaciones, Letizia debe distinguirse del resto de la población a partir de su vestimenta. Claro que, no podemos olvidar la preponderancia de los productores culturales que en este campo se presenta de manera más inmediata en Hola.com. De estas suposiciones, puedo partir para destacar las críticas mostradas en la prensa por infringir las denominadas prendas distintivas, y transformarse en la Reina austera y que recicla ${ }^{39}$. "Errores" por delimitarlo de una manera que no sea cruel, que para la periodista de $A B C$.es, María Luisa Funes, no deben pasar por alto en una entrevista del 28 de diciembre del 2014 por su libro "Estilo Letizia". Libro que desvela características de las prendas utilizadas por la Reina, pero que regresando a sus errores, permite, a la experta en moda, mostrar en su discurso ${ }^{40}$.

\footnotetext{
${ }^{38}$ Sería uno de los apartados a cumplimentar, considerando en el análisis el concepto de habitus como las maneras de obrar, pensar y sentir condicionadas por la posición además del gusto en Bourdieu, teniendo en cuenta el capital simbólico que desarrolla el sociólogo francés.
}

${ }^{39}$ Se refiere al posible conflicto entre la moda y la economía. La situación de crisis impide mostrar las ostentosidades en las Casas Reales debiendo mostrar atuendos recatados y austeros. La contradicción en las páginas es palpable resaltando como delito el repetir varias veces el mismo traje y más tarde alabando esto como moda actual. Si nos fijamos en la noticia de $A B C$.es del 17 de septiembre, el titular relata: "La chaqueta preferida de la Reina Letizia", como si se tratara del niño pequeño que quiere ponerse los mismos calcetines una y otra vez. Crítica a la chaqueta por lo siguiente: "Aunque el armario de Doña Letizia es conocido por todos, hay una chaqueta que parece ser su preferida y que hoy ha lucido por quinta vez (la negrita es del periódico, interpretable por ser una desfachatez por parte de la Reina vestirlo nada más y nada menos que cinco veces) [...] una chaqueta azul con estampado étnico" (un buen material a estudiar la etnicidad de los estampados). En el apartado del reciclaje la mención es parecida en una noticia del 24 de octubre del mismo periódico: "Para esa ocasión, la Reina volvió a reciclar vestido (el subrayado corresponde a $A B C . e s$ ), como ha hecho en numerosas ocasiones".

${ }^{40}$ Por cierto, se lee en la entrevista sobre su libro sobre Letizia: «Cierta sobriedad personal que muestra un deseo de solidarizarse con esta España en crisis»: ¿Una monarca comprometida?-Si no lo fuera, no tendría que haber puesto de moda repetir ropa. No lo hacía ni Máxima de Holanda ni nadie. Tampoco tendría por qué llevar el $80 \%$ de las veces creadores españoles. Y en el precio, aunque sea un vestido de alta costura, la diferencia es abismal. ¿Qué error suyo no tiene perdón?-Todo tiene perdón en la vida. Y debe darse cuenta de que representa a España las 24 horas del día. Una foto a las diez de la noche saliendo del cine 
De los últimos elementos a tratar en la construcción del personaje es la consideración de lo que anteriormente defino como una Reina cercana. Una Letizia Ortiz que se transforma en Reina en determinados eventos pertenecientes a la simbología real, en cambio, se convierte en Letizia cuando se la exhibe por persona normal y corriente, en sus momentos de cotidianidad. En estas informaciones, lo que ocurre es que se nos presenta las tareas diarias de una persona a la inversa, aclaro, se nos muestra a la Reina Letizia de manera cotidiana en sus tareas que en realidad son las no cotidianas, a partir de la cotidianidad que sí llevan a cabo los lectores de los medios de prensa. Habría que ajustar bastante el siguiente comentario, pero supongo que los que leen estas noticias no tienen la disposición de un avión privado para viajar en este mismo instante a Nueva York, en dos horas regresar y marchar a Finlandia, mientras que sí forma parte de la mayoría de los lectores, hacer la comida, ir a trabajar, estudiar, dar un paseo o visitar algún establecimiento o ir al cine ${ }^{41}$. Por lo tanto, el objetivo fundamental es mostrar a Letizia Ortiz como cualquier otro ciudadano ${ }^{42}$ y que el público la sienta en el trato que pertenece a su propia familia ${ }^{43}$, de ahí el nombre del primer título, del académico.

En este último apartado, de lo que pretende ser el cuerpo en la centralidad de este trabajo, y reafirmando la importancia del análisis textual, aparece la necesidad en elaborar dentro de un estudio poliédrico un marco muchísimo más amplio del apartado de lo que he propuesto que sea como receptor, es decir, una investigación que avance en la percepción del público que es quién en última instancia oye, escucha, lee, ve, la presentación que se realiza del personaje, en este caso, sobre Letizia Ortiz y que en consecuencia, en palabras de S. Hall, decodifica el mensaje producido. Pero no es que solo, el receptor lo decodifique sino que también lo recodifica en función del código, es decir de las particularidades identitarias de clase, sexo, edad o etnia de cada individuo.

Princesa con vaqueros rotos y camiseta con mensaje, que es una tontería, tiene más repercusión que una foto recibiendo a una asociación de enfermos.

${ }^{41}$ Según el marco general de medios del 2014 de la AIMC describe que el $84 \%$ de la audiencia de Internet se sitúa en la clase media (la media alta un 17,8\%, la media media, un $43,5 \%$ y la media baja $22,7 \%$ ), que por sexo el $51 \%$ son hombres y el $49 \%$. Ahora bien, en el perfil de los consumidores de las revistas el $57,5 \%$ son mujeres y el $42,5 \%$ hombres mientras que en los periódicos el $60,2 \%$ son hombres y el $39,8 \%$ mujeres. Respecto a la clase social, entre las revistas y los periódicos no hay diferencias significativas en más de un punto porcentual. Las definiciones de clase social y la metodología empleada por la asociación se presenta en la Guía de referencia del nuevo sistema de clasificación socioeconómica en el EGM, disponible en la página web de AIMC.

42 Noticia en Hola.com del 22 de octubre del 2014, "...la Reina salió de palacio estos días para hacer compras y mirar escaparates durante un paseo de incógnito por el centro de Madrid", presentándose una fotografía con las prendas que en moda se llaman de "calle". Además no se debe olvidar, que en la misma noticia se destaca que Letizia Ortiz posee dos móviles el de Reina y el personal.

${ }^{43}$ En Hola.com noticia del 25 de octubre: "Sin pensárselo dos veces, la Reina se ha puesto a lavar como una más, un gesto que ha agradado a todas ellas. Una de las lavanderas ha declarado a la Televisión del Principado que ha "alucinado" cuando la Reina ha metido las manos en el agua. ¡Con lo fría que está, no imaginaba que lo fuera a hacer, pero es muy cercana, es como nosotras!" 


\section{Conclusión:}

Finalmente, el papel que representa Letizia Ortiz es el de la mujer clásica en el patriarcado, que acompaña en las salidas y paseos, que espera en la cocina cuando los hombres de la casa se saludan, que se le reconoce su inteligencia y "saber estar" por su vestimenta, la que se le juzga por no ser una buena mujer para su marido (por aquello de los genes). Pero no solo es esto, la proyección hegemónica del personaje se encuadra dentro de la cultura humanista y elitista, pudiendo observar o contemplar la producción de dos distintos personajes el que cumple su rol dentro como mujer de la monarquía y el cercano a las gentes. Sin embargo, a largo plazo y no en un período corto de cuatro meses, se podría comprobar si existe la producción de un personaje subalterno, que apostaría a afirmar como tal, ya que la evolución que puedo apreciar del personaje es de una Letizia Ortiz de princesita adaptándose a su nuevo medio en el año 2003, mostrando su mayor recato hasta la actualidad, la conversión a Reina que parece intentar mostrarse como rebelde dentro de los márgenes establecidos ${ }^{44}$, aunque en definitiva acabara realizando las mismas tareas: antes presentaba los informativos, y ahora presenta congresos, premios 0 eventos.

\section{Referencias bibliográficas:}

- ¡HOLA!. (2015, Julio, 09). Revista ¡Hola! [Actualización Facebook]. Recuperado de https://es-es.facebook.com/revistahola.

- ¡HOLA!. (2015, Julio, 09). Revista ¡Hola! [Actualización Twitter]. Recuperado de https://twitter.com/hola.

- ABC.es. Recuperado de 2014 de.

http://www.abc.es/hemeroteca/busqueda-avanzada.

- AlMC.es. Recuperado de 2014 de:

file://C:/Users/Usuario/Downloads/resumegm314.pdf.

- AlMC.es. Recuperado de 2014 de:

file://C:/Users/Usuario/Downloads/marco15.pdf.

- $\quad$ Bacon, F. (2014): La sabiduría de los antiguos, Madrid, Tecnos, pp. 122. ISBN: 978-84-309-5920-4.

- $\quad$ Beck, U. (2001): "Vivir nuestra propia vida en un mundo desbocado: individuación, globalización y política", en Giddens, A. y Hutton, W. (coords.): En el límite: La vida en el capitalismo global. Barcelona, Tusquets, pp. 233-245. ISBN: 978-84-8310-737-9.

\footnotetext{
${ }^{44}$ En $A B C$.es, el 28 de septiembre: "La elección de un material como el cuero es algo inusual para una Reina [...] Considerado como algo más «sport» (informal) que formal, el cuero tiene hoy en día connotaciones del mundo «heavy» o rockero"; titular del 2 de octubre en el mismo diario: "Supersubmarina: «La primera vez que vimos a la Reina Letizia en un concierto fue una sorpresa»"; en $A B C$ el 28 de septiembre: "Doña Letizia en cambio, suele ir con pantalones, lo que en ocasiones suscita algún malestar". Incluso el acto más famoso de rebeldía en los últimos meses, el 23 de abril del 2015, en este caso, en la revista Telva.com, con el siguiente titular y contenido: "Doña Letizia se corta el pelo y sorprende con un bob" además de "estrena la temporada con este nuevo look de pelo mucho más radical". Disponible en: http://www.telva.com/2015/04/20/celebrities/1429559709.html.
} 
- $\quad$ Bourdieu, P. (1998): "El habitud y el espacio de los estilos de vida". En La distinción, Madrid, Taurus, pp. 597. ISBN: 84-306-0338-7.

- Busquet, J. (2012): "El fenómeno de los fans e ídolos mediáticos: evolución conceptual y génesis histórica", en Revista de Estudios de Juventud: Ídolos mediáticos y nuevos valores, № 96, pp. 13-29. ISSN: 0211-4364.

- $\quad$ Callejo, J. (2000): "Medios, género y poder", en García de Cortázar, M. y García De León, M. A. (coords.): Profesionales del periodismo: Hombres y mujeres en los medios de comunicación, Madrid, CIS/Siglo XXI, pp. 1-25. ISBN: 84-7476-310-X.

- Casareal.es. Recuperado de 2015 de: http://www.casareal.es/ES/FamiliaReal/ReinaLetizia/Paginas/biografia.aspx

- $\quad$ EIPaís.es. Recuperado de 2014 de: http://elpais.com/archivo/.

- HOLA.com. Recuperado de 2014 de: http://www.hola.com/archivo/2014/09/01/.

- Introl.es. Recuperado de 2015 de: http://www.introl.es/portfolio/auditoriade-medios-digitales/

- Kellner, D. (1998): "Vencer la línea divisoria: estudios culturales y economía política", en Ferguson, M. y Golding, P. (coords.): Economía política y estudios culturales, Barcelona, Bosch, pp. 185-212. ISBN: 84-7676-452-9.

- Kellner, D. (2011): Cultura mediática: Estudios culturales, identidad y política entre lo moderno y lo posmoderno, Madrid, Akal, pp. 381. ISBN: 97884-460-2300-5.

- López de Maturana, V. (2005): "ABC ante la cuestión vasca en la Transición y la Democracia (1975-2001)", en El Argonauta Español: http://argonauta.revues.org/1197\#tocto2n1

- Manzo, S. (2014): "Estudio preliminar", en Bacon, F.: La sabiduría de los antiguos, Madrid, Tecnos, pp. 13-72. ISBN: 978-84-309-5920-4.

- Marcuse, H. (1993): El hombre unidimensional: Ensayo sobre la ideología de la sociedad industrial avanzada, Barcelona, Planeta-Da agostini, pp. 129. ISBN: 84-395-2183-9.

- Martín Cabello, A. (2008): "Comunicación, cultura e ideología en la obra de Stuart Hall", en Revista Internacional de Sociología, Vol. LXVI, № 50, pp. 35-63. ISSN: 0034-9712.

- Paniagua Santamaría, P. (2009): Información e interpretación en periodismo: Hacia una nueva teoría de los género, Barcelona, UOC, pp. 165. ISBN: 978-84-9788-858-5.

- Rivière, M. (2009): "Fama, medios de comunicación y opinión pública", en Quaderns del CAC, № 33, pp. 119-123. ISSN: 1138-9761.

- Williams, R. (2013): Los medios de comunicación social, Barcelona, Península, pp. 238. ISBN: 978-84-9942-274-9.

- Youtube.es. Recuperado de 2015 de:

https://www.youtube.com/user/elrubiusOMG

- Youtube.es. Recuperado de 2015 de:

https://www.youtube.com/user/loulogio/videos

- Youtube.es. Recuperado de 2015 de:

https://www.youtube.com/user/TheWillyrex 